\title{
FRANCISCO BECERRA, ARQUITECTO DE DOS MUNDOS: EXTREMADURA Y AMÉRICA, EN EL SIGLO XVI" (Virreinato del Perú)
}

Lic. Yolanda Fernández Muñoz

Es evidente que las líneas de la arquitectura virreinal se dieron en el último tercio del siglo XVI, cuando las formas occidentales fueron impuestas definitivamente en la zona andina. Hasta la llegada del Virrey Toledo (1569) la tierra estaba sacudida por las guerras civiles $y$ los incas de Vilcabamba mantenian latentes ciertas formas del estado político anterior, las construcciones que se hicieron fueron muy precarias y es a partir de la década del sesenta-setenta que se estabiliza la nueva sociedad.

En arquitectura, y en general en arte, son un grupo de artistas; en su mayor parte españoles, los que recorriendo territorio de Norte a Sur, definen con su obra lo que sería la arquitectura renacentista americana; teniendo en cuenta que, dado lo avanzado de la fecha, se trata propiamente de arquitectura manierista. Esta tendencia se manifiesta en el uso de órdenes para las portadas y soportes en tanto que las cubiertas responden al gótico, para los grandes edificios, y al mudéjar para los demás. Fueron especialmente fecundos en la conformación espiritual de los pueblos hispanos, la presencia activa de artistas extremeños, que emigrados a Indias, trasvasaron a las ciudades del Nuevo Mundo formas aprendidas en sus pueblos de origen. Destacan entre ellos Francisco Becerra, cuya ejecutoria cubrió extensas zonas de los Virreinatos de la Nueva España y Perú, como luego vamos a estudiar; o Zurbarán', que ejerció un magisterio artístico de indudable resonancia en la escuela pictórica hispanoamericana, a través de sus obras embarcadas en Sevilla. Otros artistas, dignos de ser mencionados por su labor son

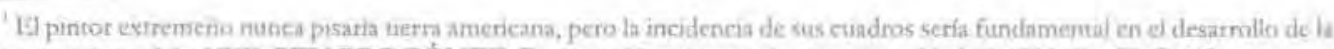

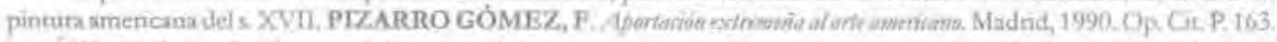

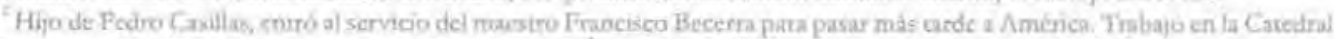

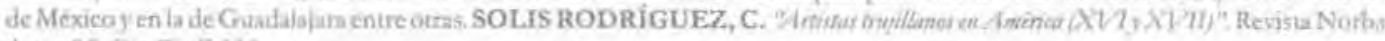

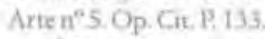

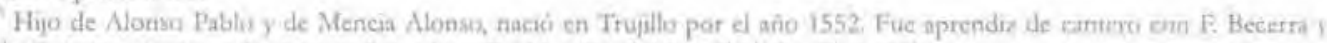
marcharia con su maestro : Amèrica, trabajando en Pueblay Guadalajara. Ihid. Op. Cir.p 133.

'Arquitecto extremerio. labró en $1608 \mathrm{el} \mathrm{balcón} \mathrm{de} \mathrm{esquma,} \mathrm{las} \mathrm{columnas} \mathrm{de} \mathrm{corredor} \mathrm{y} \mathrm{la} \mathrm{venana} \mathrm{con} \mathrm{el} \mathrm{escudo} \mathrm{cpiscopal} \mathrm{de} \mathrm{lu}$ casa del Colegro de San Juan, sobre las que se ampliô el Palacio Fisiseopal en tiempos del obispo Pala fox.

'Maestro may̧or de anquitecrura, abbañilería y canteria. Trabajó en la construeción de la fachada y coere de ta catedral de Puehla.
} 
Martin Casillas', Alonso Pablo', Nicolảs de Montiel ${ }^{4}$ o García Durango , activos en la región de Puebla de los Ängeles, formados inicialmente en Extremadura, y llevando su arte hasta las provincias de la América Hispana.

El objetivo de este trabajo es dar a conocer a un "constructor" del siglo XVI, que caminó entre dos mundos, Extremadura y América, a través de la obtención de datos(fuentes bibliográficas, arquitectónicas) para conformar un conocimiento sobre lo que hizo un arquitecto extremeño en América.

Lo que en Indias fue capítulo espléndido, tuvo en Trujillo su prólogo más prometedor. Muchas de sus obras se levantaron perfilando el paisaje trujillano como un presagio de lo que, en la otra orilla de las Españas, es prueba tangible del genio de este ilustre extremeño. Entre los trujillanos que marcharon a América destacará, Francisco Becerra, por ser un conquistador que se abrió paso en la historia, no con las armas de la guerra, sino con las de su arte.

\section{DATTOS BIOGRÁFICOSYARTÍSTICOS}

Francisco Becerra nació en Trujillo entre 1535-40 y según el "Informe de limpieza de sangre" que hizo en mayo de 1573 ante el licenciado de la Puerta, teniente de corregidor de la ciudad, para pasar a Indias, declara ser hijo de Alonso Becerra y de Constanza Hernández descendiente por ambas líneas de "hidalgos notorios" embargo existen discrepancias entre los diferentes autores consultados sobre su fecha de nacimiento?. Algunos piensan que saldría de Trujillo con tan solo 27 años".

Estuvo casado con Juana González, natural y vecina de Garciaz, "mujer de mediana estatura, de color morena", hija de Juan de Vergara y "cristiana vieja de padres e de abuelos", viven ambos en la "collación" de San Martin". Por el testamento que otorgara en 1569, sabemos que no hubo descendencia del matrimonio y que su esposo era cofrade de san Lázaro y de la Cruz, que por entonces gozaban del fervor devocional de los trujillanos.

El propio maestro nos dejó esbozado en leves trazos su retrato físico: "soy

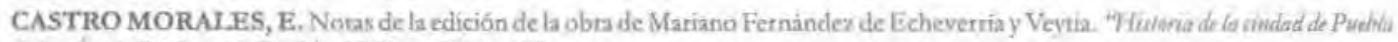

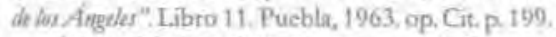

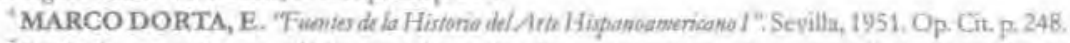

Tes decir que naceria en 1536, sin embargo los dacos comentados al priacipio de sste pártafo, algunas dicen que saldria de

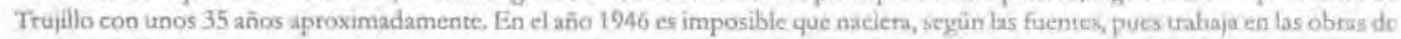
la igiesia de San Martín en el año 1553, con lo eual tendría tan sólo siete años. A.P.SM. Cuentas de Fä́brica (1538-15909).

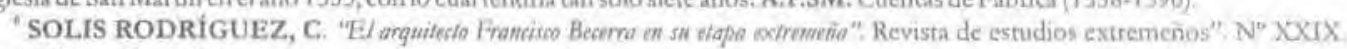
Año 1973. op. Cit. p. 304.

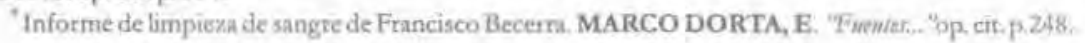


hombre de mediana estatura y delgado y poca barba y que tengo los dientes altos, delante los menos y la barba entre rubia y morena". Su carâcter serio, con un roque de altivez, parece desprenderse del interrogatorio de la Probanza de Lima, de 1585, en la que nimbado de una justa fama, optara al cargo de maestro mayor de las provincias de Perúi ${ }^{i 0}$.

La formación artística del joven maestro venía propiciada por el ambiente de la ciudad, en la que "aymas de cincuenta oficiales del oficio"." y por la misma tradición familiar, pues su abuelo materno Hernán González y su padre Alonso gozaban de gran prestigio entre los arquitectos extremeños del siglo XVI. Ambos ascendientes fueron "tales e tan buenos oficiales del dicho arte que heran tenidos por los mejores oficiales de canteria y que abia en la dicha cibdad y sus comarcas..."

En aquel clima de intenso fervor constructivo que viviera la ciudad a lo largo del siglo XVI y con tales precedentes familiares, despierta temprana la vocación artistica de Becerra. Ya en los años 1553-1558 lo encontramos, muy joven, trabajando en las iglesias de Santa María la Mayor y en San Martín, bajo la dirección de Sancho de Cabrera. En 1560 acompaña a su padre en la parroquial de Herguijuela y seis años después, ya con calificativo de maestro, iniciará una serie de obras importantes, preludio de su posterior etapa americana.

Su estética supone un contrapunto frente a las corrientes estilísticas, que se dieron cita en Trujillo a lo largo del XVI, y en las que confluyen las escuelas toledana y salmantina, de tan amplia repercusión en el paisaje arquitectónico de la Alta Extremadura. Salamanca se hace presente a través de los maestros de la Catedral de Plasencia, especialmente Rodrigo Gil de Hontañón ${ }^{15}$, y Toledo influye por medio de la misma familia Becerra, que trasvasa hasta aquí fórmulas de Covarrubias. Francisco Becerra se mueve dentro de estas coordenadas gótico-platerescas, si bien apuntando a una limpieza de líneas y formas, con predominio de los valores puramente arquitectónicos sobre los ornamentales. Esta formación ecléctica, abrirá su espíritu a otras novedades patentes en los grandes encargos a realizar en América.

La labor de Francisco Becerra en Extremadura es bastante amplia. Realizará obras de carácter religioso, civil. Entre sus obras religiosas destacan la Iglesia de Santo Domingo, de Trujillo, en la que interviene como maestro por primera vez, junto a su padre. La estructura se repite mucho, con planta alargada, una sola nave y cabecera

\footnotetext{
"Pregunta VII del inrerrogatoria. Ibid, op. Cit. p, 248.

"Provanza de Lima, 1585. MARCO DORTA, E. "Fewes.." Op. Cit. p. 288

Thid. Op Cit. p. 288.

"Que visita Trujillo en atguma ocasion CASASECA CASASECA, A. "Kndinge Gil Ac Hontañon"

Salamanca, 1888.

"TERÁN, E. "Contrilnciones o la bisinnd del erde en Enadar". N" 58, año V, de ba revista "La Bucna Esperanza". Ficuador, 1988 Op. Cit. . G.
} 
ochavada. Este modelo sería similar al utilizado en el convento dominicano de Quito" años más tarde, pero con la incorporación de capillas laterales. Además, también se le atribuyen obras como la Iglesia parroquial de Herguijuela (Cáceres), en cuya fachada emplea una composición muy repetida en las portadas peruanas del siglo XVI, de arco de medio punto, flanqueada por columnas corintias sobre las que se levanta un entablamento que sirve de base a un frontón.

Otras obras, como la Iglesia parroquial de Orellana la Vieja (Badajoz), o la Sacristia de la Iglesia de Valdetorres (Badajoz).

En lo que se refiere a los conventos, en Trujillo realizará obras en los de San Miguel, Santa Maria, San Francisco, Santa Isabel (religiosas dominicas) y la Concepción Jerónima, además de una capilla en el monasterio de Guadalupe en los años $1570 / 1^{13}$.

Entre sus obras de carácter civil destacan las residenciales de Isabel de Mendoza, donde presenta la novedad de unir balcón y puerta en ángulo, dando muestra de su eclecticismo estilístico y sobriedad en la composición y líneas. También realiza el palacio mayorazgo de Gonzalo de las Casas o Palacio de Santa Marta, también llamado "Casa dél rincón", cuya portada sigue un esquema similar al palacio de Orellana-Pizarro, que realizó su padre, el cual tiene un vestibulo con bóveda casi plana y patio cubierto con arcos de medio punto sobre columnas de capiteles corintios. A su vez realizó la escalera del palacio de Vasco de la Llave.

Para el Ayuntamiento de su ciudad natal, llevaria a cabo el embalse de la Albuhera, el puente Magasquilla o la excelente portada de la Dehesa de las Yeguas, que aún hoy se dibuja en los campos trujillanos y cuya estructura, de vano adintelado sobre columnas toscanas y frontón triangular, además de los flameros, repite en sus obras americanas. Existe la posibilidad de que haya nuevas obras en Extremadura, pero no se tiene constancia de ello en este momento.

A principios de 1575, Becerra llega a Puebla de los Ángeles y es nombrado maestro mayor de la Catedral por el Virrey Don Martín Enriquez. El día 11 de Noviembre de 1575 , presenta ante el cabildo eclesiástico las trazas para la catedral y, al año siguiente, es nombrado alarife y fiel de la ciudad de Puebla "por el tiempo que fuere la voluntad de cste cabildo" "lih. Tal vez a su llegada a Nueva España se acercase a las tierras del encomendero Gonzalo de las Casas, en Oaxaca, que habia emprendido la construcción del convento de Yanhuidán, para cuya obra trajo artistas de España. Estos prolegómenos americanos justíficarían la fama con que el maestro llega a la ciudad

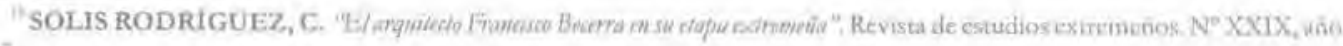
1973.

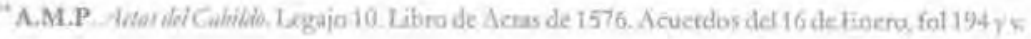


angelopolita y se hace cargo de las obras de la Catedral con el sólo título de "ser hombre preeminente en el dicho oficio y en competencia de otros muchos maestros", según propia declaración. Realiza obras en los conventos de Santo Domingo y San Luis de dominicos, en San Agustin, asf como en los pueblos comarcanos de Teotimehuacán y Cunautinchan ${ }^{17}$. Pero la obra mảs importante que realizó el arquitecto trujillano en la ciudad de México fue la consolidación de la Iglesia de Santo Domingo en la antigua Tenochtitlán.

Los pueblos comarcanos, Tlaneplanta, Cuernavaca y cl marquesado de Tepoztlan, conocicron también la actividad de Becerra, cerrando su etapa novohispana en 1581, en que aparece en la ciudad de Quito.

En su ciudad quiteña comisionado por la Audiencia, ejerce el cargo de "partidor de estancias y solares ${ }^{\prime \prime b}$, dando trazas para tres puentes y dirigicndo las obras de los conventos de Santo Domingo y San Agustin. Era un hombre querido por la autoridades, que le aseguraron la nada despreciable suma de tres mil pesos anuales. Pero el espíritu emprendedor del extremeño no se aquietaba en la ciudad de Quito, abriéndose a nuevos horizontes.

En 1583 lo encontramos en la Ciudad de los Reyes, llamado por su amigo y protector D. Martin Enríquez, ahora Virrey del Perú, que le encargó las trazas de las Catedrales de Cuzco y Lima. Si bien el virrey murió el año siguiente, la Audiencia le nombraba el 17 de junio de 1584 "maestro mayor de la Catedral", asignándole un sueldo anual de ochocientos ducados de plata y casa donde habitar cercana a la obra. Sin embargo las obras no se iniciaron prácticamente hasta 1596, en que toma posesión del virreinato D. Luis de Velasco, verdadero promotor del templo limeño, siguiendo los planos ideados por Becerra.

El 2 de abril de 1585, comparecía ante el alcalde D. Francisco de Cárdenas para hacer información probatoria de sus trabajos artísticos, solicitando del Rey el cargo de "maestro major de los reinas del Perú", pera el Consejo de Indias denegó la solicitud. En contrapartida, el 5 de junio de aquel mismo año el Cabildo lo nombraba "alarife mayor de la Ciudad".

El 25 de abril de 1605 según unos autores, ${ }^{21}$ y el 29 según otros, ${ }^{22}$ Becerra muere en

\footnotetext{
"Presenta semejanza la bóveda de esta úluma con las del coro de la lglesa de San Francisco de Puebla. CASTRO MORA B BS, E. "Notas dele nilidion."

"MARCO DORTA, E. "Fumies, "

"Lubrovie Colvildo de los Regus. Fid. 1935; Tomo X. p, 82.

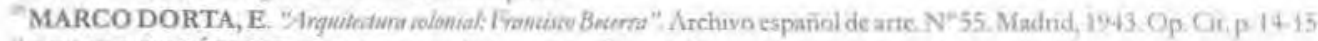

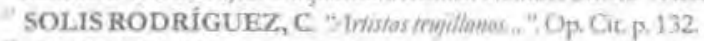

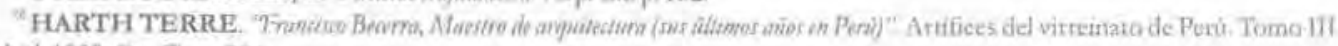
Madeid, 1952. Op. Cit p. 284.
} 


\section{Liłc. Yolanda Fernández Muñoz}

Lima y, por las fuentes consultadas, se encuentra enterrado en la que fuera capilla de San José, en la misma Catedral. Años después, el arcediano D. Juan Velásquez pedia al Consejo de Indias el envio de un maestro capaz de proseguir los planos iniciados por el extremeño y se lamentaba de que no hubiera maestro capaz "como no le ay en aquella tierra por haver muerto el que avéa que era Francisco Becerra" ${ }^{23}$. Era el mejor elogio póstumo a la memoria del trujillano.

\section{SU OBRA EN PERÚ}

Fruto de las investigaciones he obtenido una relación de obras que Becerra llevó a cabo en el Virreinato peruano ${ }^{24}$. Algunas de estas obras nos ofrecen detalladamente la labor de Becerra y en otros casos, como ocurría en Puebla y Quito, sólo son mencionadas, dejándonos ese camino por investigar.

Entre sus obras destacan la catedral de Cuzco y alguna actuación en el convento de San Francisco de la misma ciudad. En Lima realizará obras religiosas y civiles, como la Catedral, las Casas reales o la reedificación del Palacio de los Virreyes, el coro y capillas laterales de la Iglesia de San Agustín o la Iglesia nueva de San Sebastiản ${ }^{25}$. Participó además en los Fuertes del Callao o dando trazas al Hospital de Santa Ana ${ }^{2 n}$, unos embalses, planos para un corral de comedias, algún tajamar del tío, y otras obras de carácter particular, como las casas de Diego de Carvajal, la de Juan de Valvas o la portada del lieenciado Ferrer de Ayala.

\section{La Catedral de Cuzco}

Se encuentra en un ảngulo de la plaza mayor, que es un gran trapecio rodeado por casas del siglo XVI, con soportales de arcos de medio punto sostenidos sobre finas columnas de piedra y donde algún autor percibe una cierta relación con la plaza trujillana.

La polémica sobre la autoria de este edificio sigue vigente entre los historiadores consultados. Alguros poseen la certeza de que la obra no puede atribuirse a Francisco Becerra ${ }^{27}$, pero la mayoría está de acuerdo en que a pesar de no haber hallado documentación que confirme la autoria de Becerra, no bay duda de que la catedral de

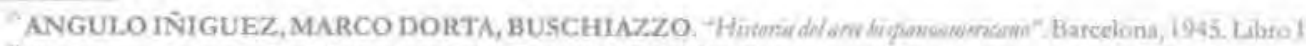

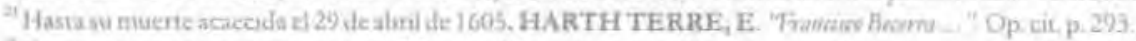

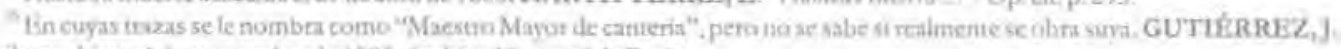
Escribano Lima, A deseptiembreade 15R5. Archivo Nacional de Perú.

-Que no liego a realizarse.

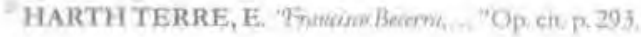




\section{Cuzco sigue fielmente su modelo, muy similar al de la catedral de Lima.}

En cfecto, para ambas catedrales adoptó Becerra la planta tipicamente española, consistente en templos de tres naves, más dos filas de capillas larerales profundas, crucero colocado casi en el centro, presbiterio de cabecera plana y todo el conjunto encuadrado dentro de un rectángulo, sin girola, ni ábside, ni brazos del crucero a cualquier otro elemento que podría romper el cubismo perfecto del volumen exterior. Para hacer más evidente esta tendencia a las formas planas, rectas, lisas, que son verdaderas constantes de la arquitectura española, ambos templos carecen de cúpula, probablemente se deba esto al temor de los temblores, tan frecuentes en ambas ciudades, pero de todos modos la carencia de un elemento tan acusado como es el domo; contribuye a acentuar el cubismo de estas catedrales.

Las bóvedas de crucería con terceletes sobre pilares cruciformes de orden toscano, es el sistema de cubierta de la catedral cuzqueña. Esta solución puede estar relacionada con el hundimiento que sufren las bóvedas de arista diseñadas por Becerra en la catedral de Lima y su sustitución por bóvedas de crucería. Lo gótico de la solución adoptada, más por razones prácticas que estilísticas, contrasta al igual que en Lima con lo renacentista de la planta y el moderado barroco de la decoración de la fachada principal.

Las variantes son escasas con la catedral limeña, como es el caso de un tramo menos $^{24}$, crucero màs ancho y limpidos sillares en los pilares cruciformes, que contrastan con los muros de mampuesto. La horizontalidad de la catedral cuzqueña es más acentuada que en Lima. Las plantas son similares, pero los aspectos que ofrecen sus alzados son diferentes, pues en Cuzco prevalece el sentido de fortaleza y tradicional colocación del coro en la nave central, mientras en Lima, la sensación es de amplias perspectivas por el traslado del coro al presbiterio y una mayor flexibilidad, luminosidad y colorido que cubre la pobreza de materiales, ladrillo y adobe estucados en los muros que forran la viga de madera y nervios, también de madera, en las cubiertas.

La catedral de Cuzco fue iniciada en 1582 por Becerra, quien modificó los primeros planos que hiciera, reemplazándolos por otros en 1598, para plasmar la estructura que en definitiva mantuvo hasta nuestros dias. A la muerte de Becerra, en 1605, le sucedieron los alarifes Bartolomé Carrión, Miguel Gutiérrez y Antonio de la Coba, Las obras finalizaron en 1654.

\section{La catedral de Lima}

Los dos primeros edificios que sirvieron como catedrales en la Ciudad de los Reyes en 1535 y $1549^{20}$, no tuvieron pretensiones arquitectónicas, fueron templos

\footnotetext{
${ }^{*}$ Que pueden deherse a um angutecto posteriot.

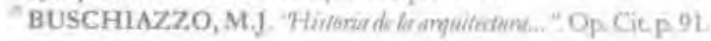


gótico-mudéjares que no agradaron a autoridades y población, por ello en 1564 Alonso Beltrán inició los trabajos de cimentación de una iglesia a la que cambiaría su orientación, ahora perpendicular a la plaza de armas. Era un proyecto de colosales dimensiones, que resultó desmesurado y abandonó en pocos años.

Francisco Becerra llega en $1582^{30}$ y se encargó de las obras, proyectando una planta rectangular con cuatro torres en las esquinas e incluso con la misma disposición de la escalera de caracol para el acceso a los campanarios, condicionado por el solar y parte de los cimientos ya levantados por Beltrán, aunque redujo las naves a tres, más dos órdenes de capillas, al igual que el modelo que trazara Pedro de Vandelvira para la catedral de Jaén o Juan de Herrera en Valladolid. Utilizó pilares cruciformes con pilastras adosadas como sistemas de soporte y separación de las naves y para ganar altura; colocó sobre el capitel un troza de entablamento que ya utilizara Siloé en la Catedral de Granada. Becerra dirigió las obras hasta ver inaugurado medio templo en $1604^{3 \mathrm{~T}}$ y una vez derribada la vieja catedral, situada a los pies de la actual, continuó los trabajos hasta su muerte, acaecida un año después. Él habia dispuesto, de conformidad con los criterios del "purismo" renacentista peninsular, bóvedas de arista de igual altura en las tres naves y más bajas en las capillas, pero casi todas se desplomaton a causa del terremoto de 1609. Los informes que entonces se solicitaron a los arquitectos de la ciudad fueron coincidentes en rebajar la altura de los pilares y emplear bóvedas de crucería, a la misma altura en las tres naves. Asi, la catedral limeña volvió a este sistema de cubiertas, mâs por necesidades que por fidelidad estilística, aunque luego se extendió dicha modalidad a otras edificaciones del virreinato.

El maestro español Juan Martínez de Arrona ${ }^{32}$ continuó los trabajos ajustándose en todo lo demás, a los diseños de Becerra. De las cuatro torres trazadas en los ángulos, igual que en Puebla, sólo se llegaron a levantar las dos de los pies en el mismo siglo XVII. Estas partes del edificio han sido las que más veces se han reedificado y variado de aspecto pues, en lo demás, la catedral limeña conserva la planta de Becerra y buena parte del alzado por él concebido y modificado por Arrona.

\section{Coro y capillas de San Agustin}

Becerra habia dispuesto, de conformidad con los criterios del "purismo" renacentista, el coro de la Iglesia de San Agustín de Lima.

La primera iglesia fue levantada en el último tercio del siglo XVI, con una traza gótico-isabelina y ornamentación mudéjar en la cubierta de la nave central y reñacentista

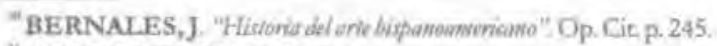

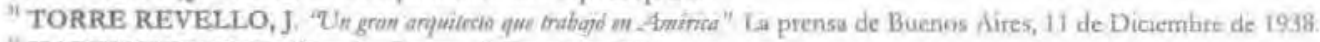

"HARTH TERRE, E. "Francisme Bencrate.". Op eit. p. 283.
} 
en las tres portadas. Será en esta iglesia en la que Becerra llevará a cabo el doble coro, situado a los pies de la misma, justo detrás de la portada principal, con una plataforma de altura intermedia sobre bóvedas. La obra sería concertada el 11 de enero de 1592.

Se trataba de completar todo el sector de las dos primeras naves transversales detrás del muro de los pies. Debia hacer dos capillas a cada lado de la nave central, más los tramos de ésta, seis. Estos, a su vez, estaban comonicados por arcos con las otras capillas laterales y la nave central, que se cubrían con bóvedas de arista y posiblemente los laterales también, aunque este dato no estaba especificado, pero este tipo de bóveda renacentista, más español, daría mayor altura al sotocoro, permitiendo mayor comunicación entre los espacios.

Las dos bóvedas del coro y las cuatro de las capillas debían estar al mismo nivel plano sobre el que se erigía el coro alto, el antecoro y los depósitos de los libros corales, de manera que las capillas colaterales tendrían menor altura que las otras capillas hornacinas de la iglesia. Subió además las paredes laterales hasta la altura del coro y no los muros laterales de la nave central, que sustentarian la techumbre mudéjar de la nave y serían elevados después por Francisco Morales, encargado de realizar las portadas de la misma iglesia.

\section{El Hospital de Santa Ana}

Se encuentra en Lima y data del año $1554^{33}$. Es un hospital para indios con diseño en cruz, formándose con dos cruceros adyacentes, uno mayor para hombres y otro menor para mujeres. Tangencial a ellos, en un extremo, se ubica un claustro que se comunica por un corredor con la iglesia, situada hacia fuera. Ambos tienen altar central y una capilla miserere. Esta tipología de hospital seria la más utilizada cuando Becerra diera las trazas para el nuevo diseño ${ }^{34}$. Sin embargo, el esquema era similar en los hospitales hispanos, con planta en forma de cruz, a finales del siglo XV.

\section{Las Casas Reales}

En 1584 el Cabildo de Lima nombra a Becerra "alarife de la ciudad", por ser "buen oficial así de cantería como de arquitectura". Sin embargo, al año siguiente, renunciaría al cargo $^{35}$ para poder concertar la obra de las Casas Reales ${ }^{3 n}$ y en $1596^{37}$, vuelve a ser

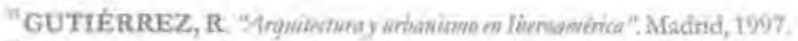

"Del euai aùn notenemos información, putes no llegó a realizarsese.

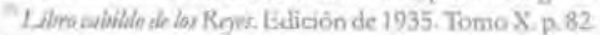

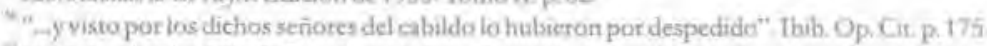

El 15 dejulio de 1585, D. Francisco de Lara. Factor de la Real Hacienda, se convene con Juan Cinco "pura que con ires earrecas

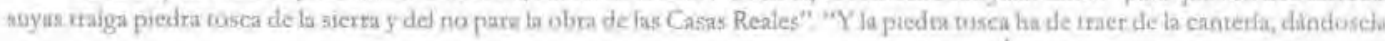




\section{Lic. Yolanda Fernández Muñoz}

nombrado alarife del cabildo.

Como consecuencia del fuerte sismo que azora la ciudad de Lima en 1586, Becerra tendrá que ocuparse del derribo y restauración de edificios dañados o la construcción.

\section{El Palacio de los Virreyes}

Comienza en 1587 por mandato del marqués de Cañete. El edificio sufre una serie de restauraciones debido al sismo de 1687 , con lo cual, cl aspecto actual del edificio no es el proyectado por Becerra. Sin embargo se ha encontrado un cuadro de la colección del Marqués de Almunia de Sevilla, que nos ofrece una ilustración de la Plaza Mayor de Lima en 1680 (antes del sismo). Este cuadro supone un excelente documento para atestiguar la labor del arquitecto trujillano.

A la izquierda del cuadro, ocupando todo el frente norte, se vé el Palacio de los Virrcyes, que era según P. Cobo, "la mayor y más suntuosa cása de todo el reino, por su gran sitio y por lo mucho que todos los virreyes han ido ilustrándola con nuevos y costosos edificios, porque apenas ha habido virrey que no la haya acrecentado con algún cuarto o pieza insigne, con que se ha llegado a la majestad que representa".

Después del terremoto de 1586 que lo dejó casi inhabitable, D. García Hurtado de Mendoza, Marqués de Cañete, lo hizo reedificar. Su sucesor D. Luis de Velasco, acabó de mejorar el palacio y fue en su tiempo cuando éste adquirió exteriormente el aspecto con que aparece en la pintura que comentamos. El frente que mira hacia la plaza es una hermosa galería y mirador de corredores hasta la mitad, donde está la puerta principal con una suntuosa portada de piedra y ladrillo que hizo labrar el virrey D. Luis de Velasco. Entre la puerta principal y la esquina de la calle del palacio, se advierten en el cuadro una galeria abierta con arcos y un mirador o balcón volado de madera con celosías de ascendencia morisca, como los que ya por esta época eran frecuentes en las casas de Lima.

La gran portada parece tener columnas jónicas flanqueando el vano adintelado del ingreso, sobre cuyo entablamento descansa el amplio balcón del segundo piso, al que dan acceso dos pequeños vanos de medio punto y uno adintelado al centró. A los lados de ésre hay columnas que reciben un frontón triangular. Una especie de ảtico rematado por un frontoncillo, donde quizá estuvieran las armas reales, remata el conjunto. Además hay unos contrafuertes de perfil que salvan la diferencia de anchura entre los dos cuerpos. A juzgar por lo que puede apreciarse en la pintura, la portada parece obra del Bajo Renacimiento fechada sobre 1600 y es posible que fuese obra del arquitecto Franciseo

sacada y puesta en el cargadero de lis carretas de piedra ha de ser de 50 arrobas $y$ a vasca de Francisco Becerta" . HERNÁNDEZ. BI.AS, Eseribano. Lima, 15 de julio de 1585, Archivo Nacional de Perú.

"HARTH TERRE, E. "Framaino Beiernt,..." Op, cit, p. 281. 
FRANCISCO BECERRA, ARQUITECTO DE DOS MUNDOS : EXTREMADURA Y AMÉRICA, EN EL SIGLO XVI" (Virreinato det Perí)

Becerra, pues se puede situar dentro de la tipologia del artista trujillano.

\section{Portada de la Casa del Licenciado Ferrer de Ayala}

Su actuación tiene lugar en 1595 con ese licenciado, Fiscal de su Majestad, para llevar a cabo la construcción de algunas obras, entre ellas una portada de cantería para su casa. Fue trazada por Becerra, pero su ejecución estuvo a cargo de los maestros Juan de Velasco y Jusepe del Castillo. La escritura de concierto se tramita ante el escribano Francisco González Balcázar el 10 de noviembre de 1595. De entre las pocas líneas que aún pueden leerse, destacan las siguientes "...y su capitel en lo alto de la columna, dórico y el arquitrabe encima del capitel será envuel to con molduras jónicas y friso llano y cornisa dórica con su corona llana, con su arco detrás de la dicha portada y sus batientes de ladrillos hasta abajo" ${ }^{\prime 35}$. Pocas palabras que nos acercan a las tendencias clásicas del maestro.

\section{Fuertes del Callao}

Interviene en la reforma del sistema defensivo de la ciudad limeña. El flanco del pacífico contaba a su favor con lo dificultoso del acceso, los riesgos de los canales australes y lo remoto de la base de aprovisionamiento; lo que reducia los riesgos de los ataques piratas. Sin embargo, la misma fragilidad dificultaba la actividad de la flota española y su conducción que, según Lonhmann Villena, los llevớ a levantar obras de arquitectura militar "de hecho más decorativas que eficaces" $"$.

Hasta la construcción del castillo de San Felipe del Callao, el sistema defensivo de las plazas se concentró en realidad en el amurallamiento de los recintos, sin contemplar elementos más complejos, internos o externos.

Becerra realiza su proyecto en 1584 y consistia en un cuerpo cúbico al estilo de las fortificaciones del siglo XVI. Sin embargo, este resultaría poco eficaz, como demostró el terremoto de 1586 o la incursión pirata de 1587.

Becerra llevará al nuevo continente, además de su gran formación artesanal, el goticismo arraigado en Trujillo en plantas y cubiertas, la decoración plateresca de raiz toledana en patios, portadas y formas donde prevalecia lo arquitectónico sobre lo ornamenta; apuntándose así los nuevos cánones del último cuarto del siglo XVI. Así, en palabras de Llaguno", Francisco Becerra "fue el mejor arquitecto que pasó a América en el buen tiempo de la arquitectura española".

Lic. Yolanda Fernández Muñoz

Lic. en Historia del Arte de la Universidad de Extremadura (España)

\footnotetext{
"HARTH TERRE, E. "Francisco Becerta, ..,". Op. cit. p. 282.

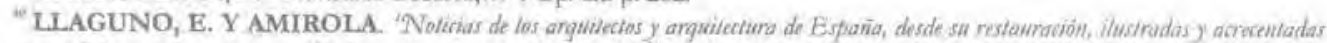
can molas, adicionesy documentas por D. Jwan Agustù CE AN BERMUDEZ". Madrid, 1829, Op. Cit. p. 56-58,

"LLAGUNO. "Nolicias de los amuitedes,
} 